\title{
Advanced Treatment of Leachate Secondary Effluent by a Combined Process of MFPFS Coagulation and Sulfate Radical Oxidation
}

\author{
Zhanmeng Liu*, Peng Zhan, Fahui Nie \\ School of Civil Engineering and Architecture, East China Jiao Tong University, \\ 808 East Shuanggang Road, Changbei District, Nanchang, 330031, China
}

Received: 22 March 2016

Accepted: 12 April 2016

\begin{abstract}
Leachate secondary effluent is usually unable to meet the national discharge permit in China and further treatment is a significant challenge because of the residual persistent pollutants. A novel magnetic composite coagulant of MFPFS was prepared from $\mathrm{Fe}_{3} \mathrm{O}_{4}$ nanoparticles and polymeric ferric sulfate (PFS). Landfill leachate secondary effluent was treated by MFPFS coagulation combined with sulfate radical oxidation due to $\mathrm{Fe}^{2+}$ activation. Higher COD and color removals were achieved using the MFPFS magnetic coagulant than by adding the coagulant PFS alone. Under the working conditions of $1: 3 \mathrm{Fe}_{3} \mathrm{O}_{4} / \mathrm{PFS}$ mass ratios, $1.2 \mathrm{~g} / \mathrm{L}$ MFPFS dosage, $50 \mathrm{~min}$ sedimentation time, and without $\mathrm{pH}$ adjustment, the removals of COD and color reached up to $60 \%$ and $80 \%$, respectively. In the oxidation process, $\mathrm{Na}_{2} \mathrm{~S}_{2} \mathrm{O}_{8}$ was activated by $\mathrm{Fe}^{2+}$ to generate sulfate radicals to oxide the residual pollutants in the effluent from MFPFS coagulation. In general, higher temperature, higher dosage, and lower $\mathrm{pH}$ were in favor of the oxidation efficiencies. Under the working conditions of $2.4 \mathrm{~g} / \mathrm{L} \mathrm{Na}_{2} \mathrm{~S}_{2} \mathrm{O}_{8}$ dosage, $0.3 \mathrm{Fe}^{2+} / \mathrm{S}_{2} \mathrm{O}_{8}{ }^{2-}$ molar ratio, $\mathrm{pH} 3.0$, and $60^{\circ} \mathrm{C}$ temperature, the COD and color removals can reach up to $75 \%$ and $95 \%$. After being treated by the combined process, no violation of Chinese effluent standards for landfill leachate was found in respect of each individual parameter, including COD, color, and other parameters like BOD, total nitrogen, and ammonia nitrogen. The combined process was a promising alternative treatment pathway for leachate secondary effluent.
\end{abstract}

Keywords: magnetic composite coagulant, coagulation, sulfate radicals oxidation, leachate secondary effluent, activation

\section{Introduction}

The sanitary landfill has been widely accepted for municipal solid waste treatment and disposal due to its lower cost of operation and maintenance as compared to others. However, landfill leachate is considered to be

*e-mail: ustblzm@163.com a heavily polluted and a likely hazardous wastewater that is produced during the biochemical decomposition of solid waste or as a result of water infiltration through solid waste. Landfill leachate exhibits considerable spatial and temporal variations. The chemical composition of landfill leachate primarily depends on site operations, refuse characteristics, and internal processes, and the major determinants are, in general, the amount and 
morphology of the deposited waste, the age of the landfill and the corresponding landfill fermentation stage, the depositing technology, and the environmental conditions (e.g., temperature and rainfall) [1]. The treatment of landfill leachate is complicated and expensive because of the high loading, complex chemical composition, and seasonally variable volumes. Many techniques for treating landfill leachate have been developed, including physical, physical-chemical, and biological process [2]. It is difficult to obtain satisfactory treatment efficiency using individual treatment methods. No single unit process is available for proper landfill leachate treatment. Among those, biological degradation is the most prevalent technology used for treating landfill leachate and is often used as a preferred process due to its low cost [3]. However, during the operation of landfills, the COD value and ammonium nitrogen concentration increase and the bio-degradability of organic pollutants decreases, and meanwhile the $\mathrm{C}, \mathrm{N}$, and $\mathrm{P}$ ratios become unbalanced. These would lead to the biological technology being more difficult to effectively treat landfill leachate alone [4]. After being treated by the biological process, there are still many residual persistent pollutants in the effluent, which is necessary to be further treated since it is always unable to meet the national discharge permit in China. Treatment of leachate secondary effluent is a significant challenge because of the residual persistent pollutants. Engineering practice shows that there is no perfect process for the treatment of leachate secondary effluent. Therefore, it is strategically important to develop an economical technical process for the treatment of leachate secondary effluent.

Coagulation is a core environmental protection technology that has a wide range of applications in wastewater treatment projects. When combined with other appropriate technologies, coagulation is a viable option for the treatment of various types of wastewater due to its simplicity and cost-effectiveness. For example, this method has been used in the pre- or post-treatment of landfill leachate to enhance the biodegradability of the leachate or to remove residual recalcitrant pollutants [56]. Coagulation efficiency is fundamentally determined by the inherent properties of the coagulants and wastewater quality [7]. With the rapid development of nanotechnology, magnetic nanoparticles have been widely applied in the field of water and wastewater treatment. $\mathrm{Fe}_{3} \mathrm{O}_{4}$ nanoparticles are a type of material characterized by having a larger specific surface area, exhibiting a stronger adsorption capacity, and easy separation [8]. Composite magnetic coagulants are considered to have better coagulation performance than traditional coagulants since their magnetic components may improve coagulative behavior. Zhang [9] successfully synthesized a novel ferromagnetic nanoparticle of composited PACls. The experiment indicates that the addition of $\mathrm{Fe}_{3} \mathrm{O}_{4}$ can not only effectively increase COD removal but also significantly accelerate the sedimentation rate of particles during coagulation. A study conducted by Jiang [10] illustrates that coagulation performance is significantly better when a new type of composite flocculant prepared by introducing $\mathrm{Fe}_{3} \mathrm{O}_{4}$ nanoparticles into polyferric chloride is applied to algae removal than when polyferric chloride is used alone. $\mathrm{Fe}_{3} \mathrm{O}_{4}$ nanoparticles can improve floc density and settling performance, thereby enhancing the removal of Microcystis aeruginosa. $\mathrm{Fe}_{3} \mathrm{O}_{4}$ nanoparticles and an organic flocculant (chitosan or polyacrylamide) are combined to prepare the inorganic organic composite flocculant that is applied to the wastewater treatment [1112]. The combination of these materials has been found to generate a strong synergistic effect that can significantly improve coagulation performance.

Although coagulation can considerably remove COD, color, and other pollutants from wastewater, this method may not always result in satisfactory treatment efficiencies when applied alone and its effluent can often not meet the national discharge permit. Advanced oxidation processes (AOPs) have been widely applied in the treatment of wastewater containing different organic compounds that are non-biodegradable and/or toxic to microorganisms. Typical AOP systems for leachate treatment had been widely studied, including electro catalytic oxidation [13-14], wet air oxidation [15-16], ozonation [17], and Fenton [18] or Fenton-like oxidation [19] as well as their combination [20]. In recently years, Persulfate $\left(\mathrm{S}_{2} \mathrm{O}_{8}^{2-}\right)$ has drawn increasing attention as an alternative oxidant in oxidation of contaminants and is considered to be a promising oxidant [21]. Persulfate can be activated to form a stronger oxidant of sulfate radical by heat [22], transition metal ions [23], or UV light [24]. It has been demonstrated by related studies that a broad spectrum of organic pollutants can be rapidly degraded in surfate radical oxidation [25]. The advanced oxidation process based on sulfate radical has a strong oxidative capacity and low cost, which facilitates its potential application in wastewater treatment. However, it is rarely reported in research that a sulfate radical was applied in the treatment of leachate.

So in this work, a novel magnetic composite coagulant of MFPFS was prepared from $\mathrm{Fe}_{3} \mathrm{O}_{4}$ nanoparticles and PFS and was introduced to remove the residual pollutants from leachate secondary effluent combined with sulfate radical oxidation due to $\mathrm{Fe}^{2+}$. The objective of this study was to examine whether the new combined process was a feasibly integrated technique for efficiently treating leachate secondary effluent and find the best operation parameters as reference for engineering applications.

\section{Material and Methods}

\section{Wastewater Samples}

The experimental wastewater was a biological pretreated leachate sample taken from a municipal solid waste landfill disposal plant in Jiujiang City, Jiangxi Province, PR China. The malodorous wastewater was brown and contained some suspended materials. Typical characteristics of the wastewater are presented as follows: COD 580-760 mg/L, color 280-360 times, $\mathrm{pH}$ 6.4-6.7, and ammonia nitrogen $62-74 \mathrm{mg} / \mathrm{L}$. 


\section{Coagulation Experiments}

With and without prior $\mathrm{pH}$ adjustment and for different dosages, coagulation experiments were performed by jar test. The $\mathrm{pH}$ values of samples were adjusted to the desired levels by the addition of appropriate amounts of $\mathrm{H}_{2} \mathrm{SO}_{4}$ or $\mathrm{NaOH}$ solution. The time and speed of mixing for rapid and slow mixing were set automatically by means of a controller. Briefly, $800 \mathrm{ml}$ of wastewater were added with a certain amount of coagulant, after which the test was conducted by subjecting the solution to 1 min of rapid mixing followed by 10 min of slow mixing. Next, the mixed samples were allowed to settle without agitation for certain time. The supernatant was withdrawn from the beakers and used for chemical analysis and further treatment by sulfate radical oxidation.

\section{Sulfate Radical Oxidation Experiments}

With and without prior $\mathrm{pH}$ adjustment, sulfate radical oxidation was conducted using $\mathrm{Na}_{2} \mathrm{~S}_{2} \mathrm{O}_{8}$ as oxidant. $100 \mathrm{~mL}$ of leachate secondary effluent was added into a $250 \mathrm{ml}$ Erlenmeyer flask. Certain amount of $\mathrm{Na}_{2} \mathrm{~S}_{2} \mathrm{O}_{8}$ and $\mathrm{Fe}^{2+}$ were added to the solution. Then the mixed solution was shaken at $150 \mathrm{rpm}$ using a shaking water bath at a controlled temperature. Oxidation was initiated by the addition of a certain amount of $\mathrm{Na}_{2} \mathrm{~S}_{2} \mathrm{O}_{8}$. The oxidation time was set for 12 hours.

\section{Analysis Methods}

COD, BOD, total nitrogen, ammonia nitrogen, and color were measured according to the Manual Standard Methods for the Examination of Water and Wastewater drawn by the Chinese Environmental Protection Agency. $\mathrm{pH}$ was measured using a $\mathrm{pH}-$ Meter (model PHS-3C). The chemical reagents used here were all analytical grade purchased from Shanghai Chemical Technology Company, China.

\section{Results and Discussion}

\section{MFPFS Coagulation Process}

Effect of mass ratio of $\mathrm{Fe}_{3} \mathrm{O}_{4} / \mathrm{PFS}$ in MFPFS on coagulation performance

The MFPFS reagents with different $\mathrm{Fe}_{3} \mathrm{O}_{4} / \mathrm{PFS}$ mass ratios were prepared and coagulation experiments of the newly prepared reagents were performed under the same conditions and the results are shown in Fig.1. As shown in Fig.1, higher or lower mass ratios of $\mathrm{Fe}_{3} \mathrm{O}_{4} / \mathrm{PFS}$ were not facilitated regarding coagulation performance. With an increase in the mass ratio of $\mathrm{Fe}_{3} \mathrm{O}_{4} / \mathrm{PFS}$, the COD and color removals first slowly increased and then gradually declined. The color removal rate reached its highest value of $83 \%$ when the mass ratio was $1: 4$. When the mass ratio was increased to $1: 3$, the COD removal rate reached its highest value at $62 \%$, and the color removal rate reached

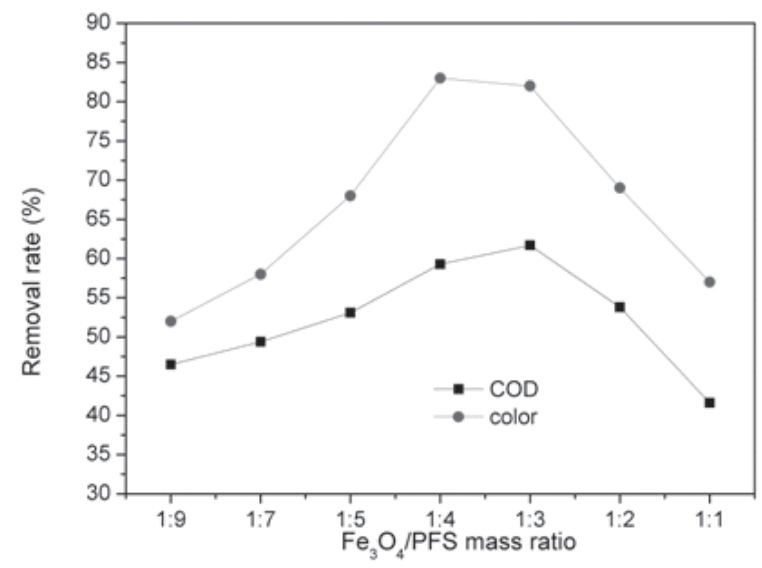

Fig. 1. Coagulation performance of MFPFS at different mass ratios of $\mathrm{Fe}_{3} \mathrm{O}_{4} / \mathrm{PFS}$.

$81 \%$. As the mass ratio continued to increase, the COD and color removals became reduced to a certain degree. When the mass ratio was 1:1, the COD and color removals were only $42 \%$ and $57 \%$, respectively. The COD removals reached up to the highest under the mass ratio of 1:3. Even if color removal was reduced slightly, the removal ratio was still high. Therefore, the optimum mass ratio of $\mathrm{Fe}_{3} \mathrm{O}_{4} / \mathrm{PFS}$ for preparing MFPFS was 1:3.

\section{Effect of $\mathrm{pH}$ on Coagulation Performance}

Wastewater $\mathrm{pH}$ is an important parameter in the coagulation process. It affects the pollutant form and the Zeta potential of colloid granule and then affects coagulation performance. In order to investigate the possible effect of initial $\mathrm{pH}$ and obtain the optimum $\mathrm{pH}$ at which the coagulation process performs most effectively, the $\mathrm{pH}$ of landfill leachate was adjusted to desired value. The effect of $\mathrm{pH}$ variation on coagulation performance was examined and the results are shown in Fig. 2. It can be clearly seen from Fig. 2 that the COD and color removals were first on the steep increase and then on the

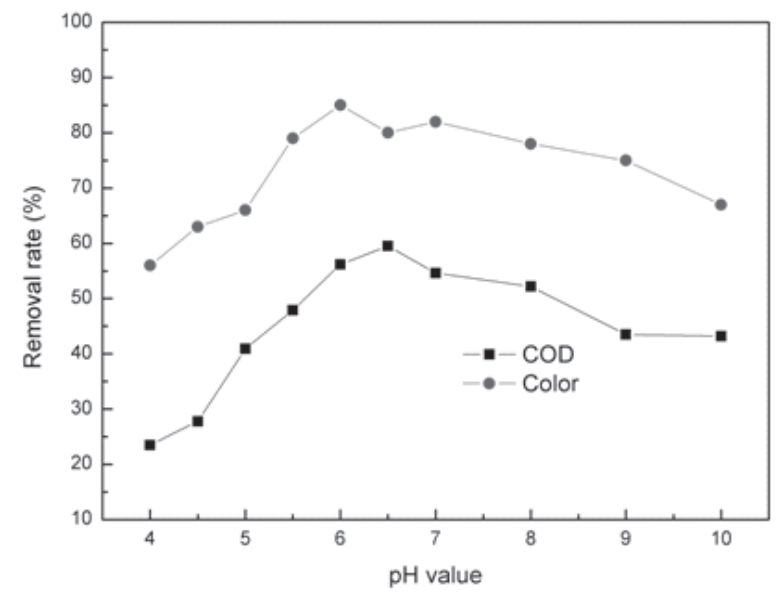

Fig. 2. Coagulation performance of MFPFS at different $\mathrm{pH}$ levels. 
very slow decline. When $\mathrm{pH}$ value was 4.0 , the COD and color removal rates were the lowest - at $24 \%$ and $56 \%$, respectively. When $\mathrm{pH}$ was 6.0 , color removal reached its highest level at $85 \%$. When $\mathrm{pH}$ increased to $6.5, \mathrm{COD}$ removal reached its highest value at $60 \%$, and color removal $80 \%$. When $\mathrm{pH}$ was increased from 6.5 to 8.0 , the COD and color removals slowly decreased with an increase in $\mathrm{pH}$ value. However, COD and color removal still reached $52 \%$ and $78 \%$, respectively, at $\mathrm{pH}$ 8.0. This illustrates that the optimum wastewater $\mathrm{pH}$ value scope was wide. In general, the coagulation performances were good in the scope of from $\mathrm{pH} 6.0$ to $\mathrm{pH}$ 8.0. Since the initial $\mathrm{pH}$ value was generally in the feasible range of coagulation and considering $\mathrm{pH}$ adjustment was uneconomical in practical engineering terms for an indistinct increase of COD removal, no $\mathrm{pH}$ adjustment was carried out during the followed trials.

\section{Effect of Sedimentation Time on Coagulation Performance}

The sedimentation process aims to separate the solid (mainly flocs) from the wastewater and produce the treated supernatant. The effect of sedimentation time on the coagulation performance is shown in Fig. 3. Both COD and color removals were on a sharp upward trend with the sedimentation time increasing from 10 to $50 \mathrm{~min}$, while keeping nearly constant after that. Sedimentation time is an important factor affecting the quality of treated supernatant. The fine solid particle left in the supernatant caused by scant sedimentation time is a contribution not only to the pollutants in supernatant but also to the burden of the latter treatments. Excessive sedimentation time maybe benefits better coagulation performance. However, this needed a larger footprint and then results in increasing much more capital construction cost investment. Considering the COD and color removal variations in general, it was suggested that the optimum sedimentation time was about 40 to 50 minutes under the given conditions.

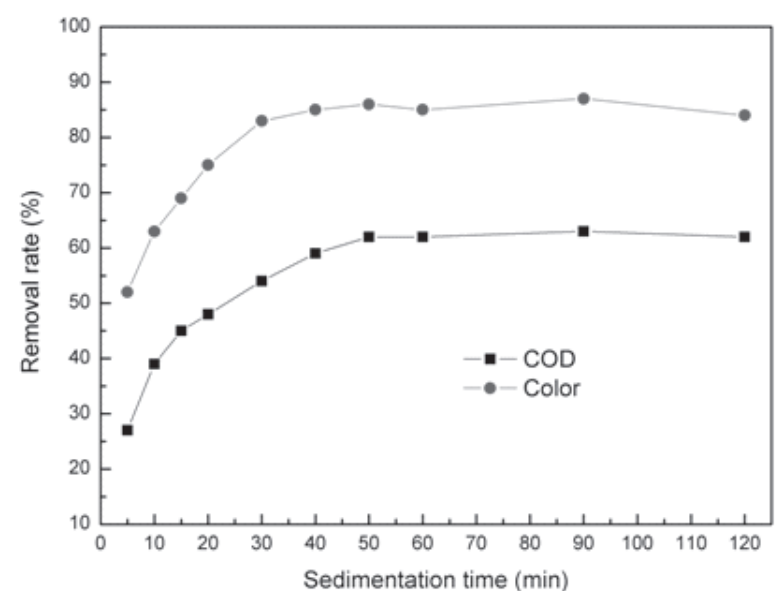

Fig. 3. Coagulation performance of MFPFS at different sedimentation times.

\section{Coagulation Performance of PFS and MFPFS at Different Dosages}

The coagulation performance of PFS and MFPFS at different dosages is shown in Fig. 4, where coagulation performance of MFPFS was obviously better than that of PFS under the same conditions. Coagulation performance had been greatly improved by the introduction of $\mathrm{Fe}_{3} \mathrm{O}_{4}$ nanoparticles. As the dosages of PFS and MFPFS increase, COD and color removals tended to initially increase quickly followed by a slow decline. When the dosage is $0.9 \mathrm{~g} / \mathrm{L}, \mathrm{COD}$ removal with the MFPFS coagulant reached its maximum at $56 \%$. By contrast, COD removal with PFS alone was only $45 \%$. COD removal when MFPFS was added was $11 \%$ higher than when only PFS was added. At this dosage, color removal of MFPFS and PFS were $82 \%$ and $69 \%$ respectively. Color removal when MFPFS was added was $13 \%$ higher than when only PFS was added. The reason is that, firstly, $\mathrm{Fe}_{3} \mathrm{O}_{4}$ nanoparticles with larger specific surface area and adsorption capacity can become the cores of floc in the coagulation process, playing the role of heterogeneous nucleation [10] and, consequently, the density and settling property of the coagulation body were improved, and the floc formation, aggregation, and settling time were shortened, thereby enhancing the coagulation of PFS [9]. The second (with increased dosage) $\mathrm{Fe}_{3} \mathrm{O}_{4}$ became easier to combine with the coagulation body of the coagulant to form a more compact magnetic flocculation due to its magnetic property. Moreover, mutual attraction between magnetic particles was enhanced, thus increasing the number of particles that aggregate into large aggregates and ultimately leading to a good coagulation effect [26].

As shown in Fig. 4, when the dosage of MFPFS increased from 2.0 to $2.5 \mathrm{~g} / \mathrm{L}$, the $\mathrm{COD}$ and color removals decrease from $62 \%$ to $46 \%$, and from $78 \%$ to $71 \%$, respectively. This indicated that overdosing of coagulant would deteriorate the coagulation performance. The reason is that an increased dosage of MFPFS causes a greater dosage of $\mathrm{Fe}_{3} \mathrm{O}_{4}$. Thus, self coagulation would

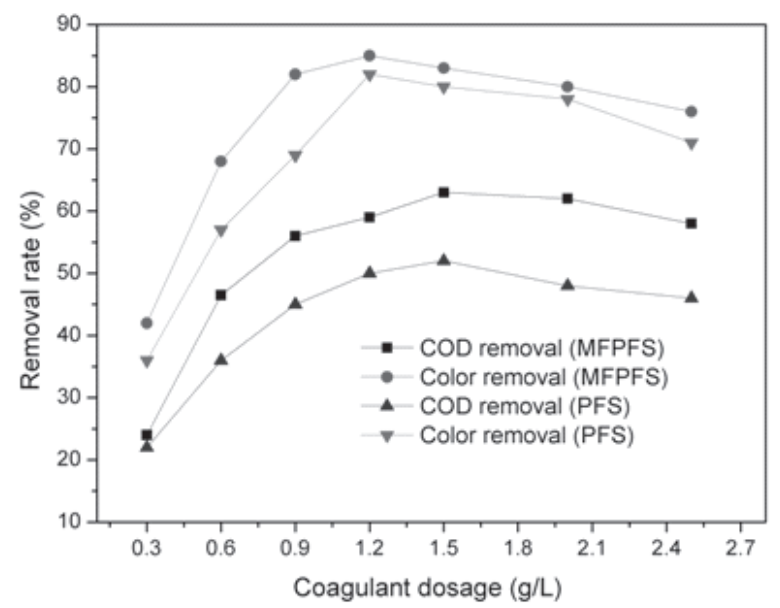

Fig. 4. Coagulation performance of PFS and MFPFS at different dosages. 
occur between $\mathrm{Fe}_{3} \mathrm{O}_{4}$ nanoparticles, which would no longer combine with the coagulation body of the coagulant to form a more compact magnetic coagulation. As such, these nanoparticles can no longer facilitate heterogeneous nucleation, resulting in poor coagulation performance. In addition, according to the charge neutralization theory, hydrolyzed products of the added coagulant can interact with negative colloids and neutralize their charges, which cause colloid destabilization and removal. With more than the appropriate dosage than the amount required for coagulation, the colloids can absorb the cations then become positively charged, resulting in renewed stability because of electrical repulsion, thus leading to poor coagulation performance [27]. Overdosing the coagulant not only weakened coagulation efficiency but also increased the cost. With MFPFS dosage in the scope from $0.9 \mathrm{~g} / \mathrm{L}$ to $2.0 \mathrm{~g} / \mathrm{L}$, the COD and color removals still reached up to $56 \%$ and $80 \%$. These illustrate that the optimum MFPFS dosage scope was wide at the experimental conditions, which makes dosage control and coagulant popularization easier.

On the basis of the above analysis, the optimum conditions for the treatment of landfill leachate by MFPFS coagulation are at $1: 3$ mass ratio of $\mathrm{Fe}_{3} \mathrm{O}_{4} / \mathrm{PFS}$ in MFPFS, approximately $1.2 \mathrm{~g} / \mathrm{L}$ MFPFS dosage, and approximately pH 6.5 (without adjusting pH). Under these conditions, the removal rates of COD and color reached up to $62 \%$ and $85 \%$, respectively.

\section{Sulfate Radical Oxidation Process}

After treatment by MFPFS coagulation, the typical parameters of the effluent were: COD 235-282 mg/L, color 70-100 times, and $\mathrm{pH}$ 6.1-6.5. The effluent of MFPFS coagulation was further subject to treatment by sulfate radical oxidation due to $\mathrm{Fe}^{2+}$ activation.

\section{Effect of $\mathrm{Na}_{2} \mathrm{~S}_{2} \mathrm{O}_{8}$ Dosage on Oxidation Performance}

Oxidant dosage is an important parameter in the sulfate radical oxidation process. The effect of $\mathrm{Na}_{2} \mathrm{~S}_{2} \mathrm{O}_{8}$ dosage on oxidation performance is shown in Fig. 5, which shows that a high $\mathrm{Na}_{2} \mathrm{~S}_{2} \mathrm{O}_{8}$ dosage generally favored COD and color removals. Generally, the trends of the COD removal and color removal were similar to $\mathrm{Na}_{2} \mathrm{~S}_{2} \mathrm{O}_{8}$ dosage, and increasing $\mathrm{Na}_{2} \mathrm{~S}_{2} \mathrm{O}_{8}$ dosage would improve oxidation performance. Observing the COD removal curve, it can be seen that COD removal significantly increased with $\mathrm{Na}_{2} \mathrm{~S}_{2} \mathrm{O}_{8}$ dosage from 0.4 to $2.4 \mathrm{~g} / \mathrm{L}$. When the oxidant dosage was $2.4 \mathrm{~g} / \mathrm{L}$, the COD removal rate reached up to $72 \%$. When the $\mathrm{Na}_{2} \mathrm{~S}_{2} \mathrm{O}_{8}$ dosage was continually increased from 2.4 to $3.2 \mathrm{~g} / \mathrm{L}$, the COD removal percentage did not significantly increase and remained relatively steady. The sulfate radical oxidation had a strong capacity of decoloration from leachate secondary effluent. When the oxidant dosage was $1.6 \mathrm{~g} / \mathrm{L}$, the color removal rate reached up to $90 \%$, and in the range of $\mathrm{Na}_{2} \mathrm{~S}_{2} \mathrm{O}_{8}$ dosage from 2.0 to

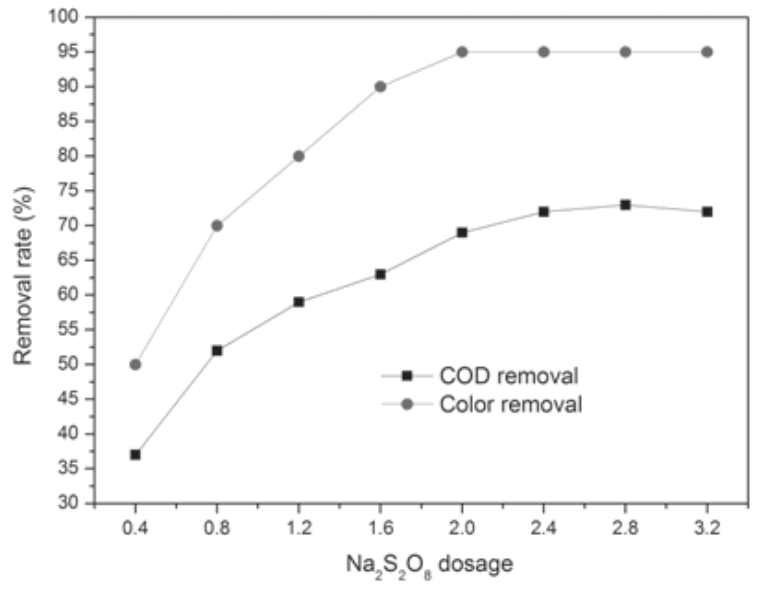

Fig. 5. Oxidation performance of sulfate radical at different $\mathrm{Na}_{2} \mathrm{~S}_{2} \mathrm{O}_{8}$ dosages.

$3.2 \mathrm{~g} / \mathrm{L}$, the effluent color nearly completely disappeared and the color removals were all more than $95 \%$.

Effect of $\mathrm{Fe}^{2+} / \mathrm{S}_{2} \mathrm{O}_{8}{ }^{2}$ Molar on Oxidation Performance

A suitable $\mathrm{Fe}^{2+} / \mathrm{S}_{2} \mathrm{O}_{8}{ }^{2}$ molar ratio is necessary in the sulfate radical oxidation due to $\mathrm{Fe}^{2+}$ activation. Too high and too low $\mathrm{Fe}^{2+} / \mathrm{S}_{2} \mathrm{O}_{8}{ }^{2}$ molar ratios are unfavorable to oxidation performance. As shown in Fig.6, a suitable $\mathrm{Fe}^{2+} /$ $\mathrm{S}_{2} \mathrm{O}_{8}{ }^{2}$ molar ratio favored oxidation performance. COD removal first remarkably increased with $\mathrm{Fe}^{2+} / \mathrm{S}_{2} \mathrm{O}_{8}^{2}$ molar ratio from 0.1 to 0.3 and then declined with $\mathrm{Fe}^{2+} / \mathrm{S}_{2} \mathrm{O}_{8}^{2}$ molar ratio from 0.3 to 0.8 . The peak removal rate of COD appeared at $\mathrm{Fe}^{2+} / \mathrm{S}_{2} \mathrm{O}_{8}{ }^{2}$ molar ratio 0.3 , with $72 \% \mathrm{COD}$ removal. When the $\mathrm{Fe}^{2+} / \mathrm{S}_{2} \mathrm{O}_{8}{ }^{2}$ molar ratio was increased to 0.6 , the COD removal rate declined to $56 \%$. This likely occurred because the $\mathrm{Fe}^{2+}$ dosage added was greater than the amount required for activation. Observing the removal curve, it can be seen that the color removal rate first

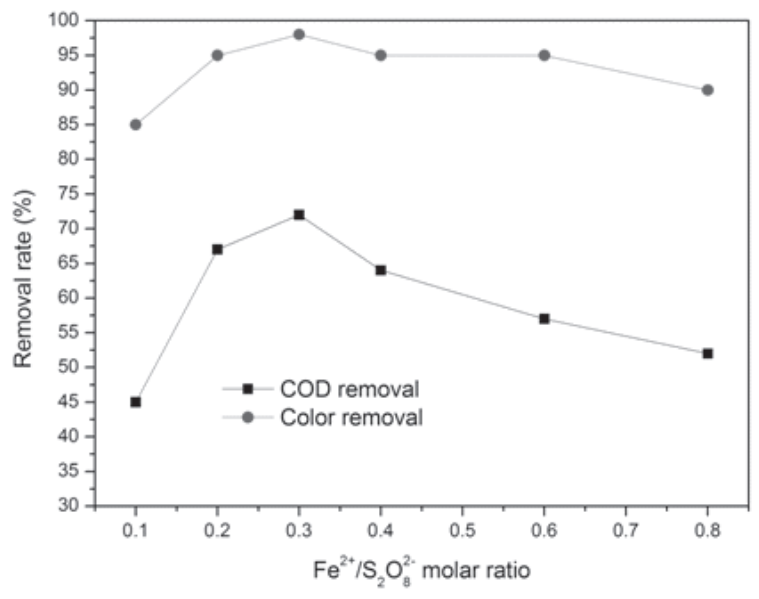

Fig. 6. Oxidation performance of sulfate radical at different $\mathrm{Fe}^{2+}$ $\mathrm{S}_{2} \mathrm{O}_{8}{ }^{2-}$ molar ratios. 
increased and then slightly declined with the $\mathrm{Fe}^{2+} / \mathrm{S}_{2} \mathrm{O}_{8}{ }^{2}$ molar ratio. Furthermore, it should be mentioned that the effluent color was always lower than 40 times in the whole $\mathrm{Fe}^{2+} / \mathrm{S}_{2} \mathrm{O}_{8}^{2}$ molar ratio and met the discharge permission (lower than 40 times) established by the Chinese Environmental Protection Agency. In consideration of COD removal and color removal, it was suggested that the application of $\mathrm{Fe}^{2+} / \mathrm{S}_{2} \mathrm{O}_{8}^{2}=0.3$ would be appropriate for wastewater treatment.

\section{Effect of $\mathrm{pH}$ on the Oxidation Performance}

$\mathrm{pH}$ is also an important parameter in treating wastewater by sulfate radical oxidation. As shown in Fig. 7 , in general the trends of COD removal and color removal were similar to $\mathrm{pH}$, and heightening $\mathrm{pH}$ would weaken oxidation performance. Both the COD removal and color removal were the highest at $\mathrm{pH} 3$, and the removal rates reached $75 \%$ and $98 \%$, respectively. Observing the COD removal curve, it can be seen that the COD removal rate first slowly declined with $\mathrm{pH}$ from 3 to 4 and then rapidly declined with $\mathrm{pH}$ from 4 to 7 . When the $\mathrm{pH}$ value increased to 7.0, the COD removal rate declined to $39 \%$. As for color removal, the removal rate slightly declined with $\mathrm{pH}$ from 3 to 5 and then remarkably declined with $\mathrm{pH}$ from 5 to 7 . It had been reported that heightening $\mathrm{pH}$ has a dual effect (positive and restrictive) on pollutant removal in sulfate radicals oxidation based on thermal activation. On the one hand, heightening $\mathrm{pH}$ is in favor of $\mathrm{Na}_{2} \mathrm{~S}_{2} \mathrm{O}_{8}$ activation generating sulfate radicals and then enhancing oxidation capacity. On the other hand, heightening $\mathrm{pH}$ can elevate the alkalinity level, which results in enlarging the side reactions of sulfate radicals with $\mathrm{CO}_{3}{ }^{2-}$ and $\mathrm{HCO}_{3}^{-}$, thus weakening the oxidation efficiencies. As a whole, it is reflected (as shown in Fig. 5) that the second parameter played a key role and heightening $\mathrm{pH}$ would deteriorate the oxidation efficiencies in the treatment of the wastewater. The result was similar to that provided in a study conducted by Shen to evaluate the oxidation efficiency of diphenylamine by persulfate [28]. Considering COD

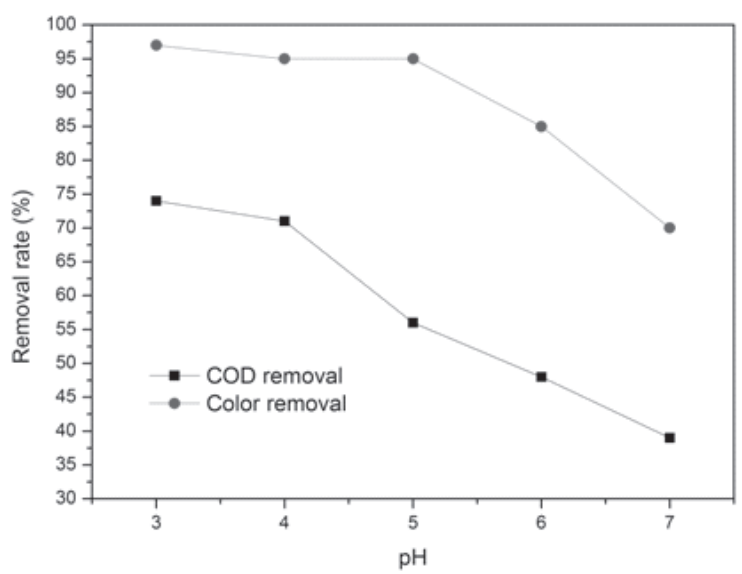

Fig. 7. Oxidation performance of sulfate radical at different $\mathrm{pH}$ values.

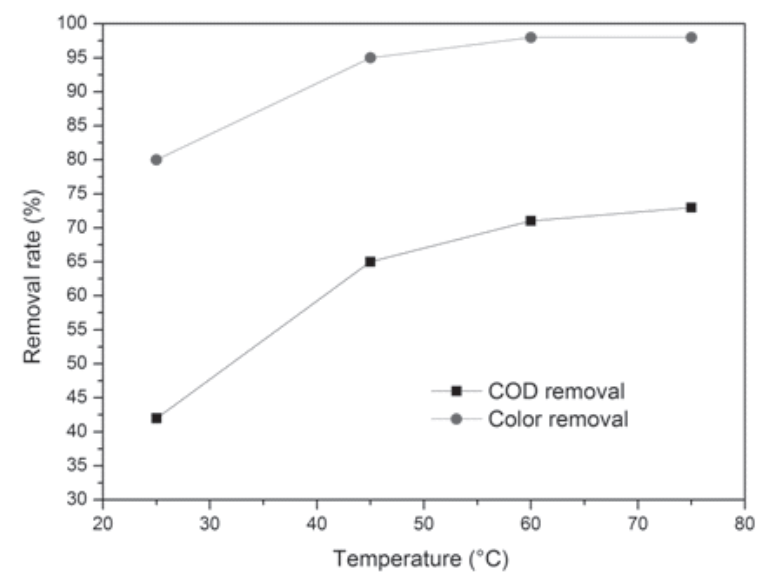

Fig. 8. Oxidation performance of sulfate radical at different temperatures.

removal and color removal, it was suggested that applying pH 3-4 would be appropriate for wastewater treatment.

Effect of Temperature on Oxidation Performance

It can be seen from Fig. 8 that high temperatures generally favor oxidation performance. The oxidation efficiencies were better at higher temperatures than those at low temperatures under the same conditions. When the temperature was $25^{\circ} \mathrm{C}$, COD removal and color removal were only $43 \%$ and $80 \%$, respectively. When the temperature was increased to $45^{\circ} \mathrm{C}, \mathrm{COD}$ and color removals reached up to $65 \%$ and $95 \%$, respectively. However, it could be found that although the higher temperature resulted in higher COD removal and higher color removal, oxidation efficiency improvement due to temperature elevation was gradually weakened. Improvement due to the elevation activation temperature became poor when continuously increasing the activation temperature from $45^{\circ} \mathrm{C}$ to $75^{\circ} \mathrm{C}$. As a consideration of COD removal and color removal, it was suggested that the application of $45-60^{\circ} \mathrm{C}$ would be appropriate for wastewater treatment.

The above results demonstrated that sulfate radical oxidation based on $\mathrm{Fe}^{2+}$ activation could adequately remove refractory organics from leachate secondary effluent. This indicated that sulfate radical oxidation can readily degrade organic matter in wastewater.

\section{Removal Efficiencies of Pollutants by the Combined Process of MFPFS Coagulation and Sulfate Radical Oxidation}

The pollutants in the leachate secondary effluent are not only indicated as COD and color, but also $\mathrm{BOD}_{5}$, ammonia nitrogen, and total nitrogen. The removal efficiencies of these parameters were also investigated under the optimized conditions. In this experiment, the coagulant dosage of MFPFS was fixed at $1.2 \mathrm{~g} / \mathrm{L}$ in the 
Table 1. Concentration changes of pollutants $(\mathrm{mg} / \mathrm{L})$.

\begin{tabular}{|c|c|c|c|c|}
\hline Item & $\begin{array}{c}\text { Leachate } \\
\text { secondary } \\
\text { effluent }\end{array}$ & $\begin{array}{c}\text { After } \\
\text { coagulation }\end{array}$ & $\begin{array}{c}\text { After } \\
\text { oxidation }\end{array}$ & $\begin{array}{c}\text { National } \\
\text { discharge } \\
\text { permit }\end{array}$ \\
\hline COD & 624 & 261 & 74 & 100 \\
\hline BOD & 190 & 60 & 24 & 30 \\
\hline Color & 350 & 85 & 5 & 40 \\
\hline $\begin{array}{c}\text { Ammonia } \\
\text { nitrogen }\end{array}$ & 70 & 65 & 18 & 25 \\
\hline $\begin{array}{c}\text { Total } \\
\text { nitrogen }\end{array}$ & 110 & 104 & 35 & 40 \\
\hline
\end{tabular}

Note: color calculated as times

coagulation process; the conditions in the oxidation process were: $\mathrm{Na}_{2} \mathrm{~S}_{2} \mathrm{O}_{8}$ dosage $=2.0 \mathrm{~g} / \mathrm{L}, \mathrm{Fe}^{2+} / \mathrm{S}_{2} \mathrm{O}_{8}{ }^{2}=0.3$, $\mathrm{pH}=3.0$, and $\mathrm{T}=60^{\circ} \mathrm{C}$. After treatment by the combined process, the typical parameters of the wastewater are listed in Table 1 .

As shown in Table 1, the combined processes can result in satisfactory treatment efficiencies. The concentration of COD decreased from $624 \mathrm{mg} / \mathrm{L}$ to $261 \mathrm{mg} / \mathrm{L}$ by MFPFS coagulation and further decreased from $261 \mathrm{mg} / \mathrm{L}$ to $74 \mathrm{mg} / \mathrm{L}$. It can be seen that the reduction of color was significant and the color completely disappeared (after oxidation), which indicated that the combined processes have a notable capacity for removing color. Concentration changes of ammonia nitrogen and total nitrogen before and after treatment were investigated. The coagulation process hardly removed ammonia nitrogen and total nitrogen while sulfate radical oxidation exhibited good capacity for ammonia nitrogen and total nitrogen removals. The concentration of ammonia nitrogen and total nitrogen decreased to $18 \mathrm{mg} / \mathrm{L}$ and $35 \mathrm{mg} / \mathrm{L}$, respectively. Certainly, it should be mentioned that after being treated by the combined process no violations of Chinese effluent standards for landfill leachate were found in respect to each individual parameter.

\section{Conclusion}

In this work, the application of the combined process of MFPFS coagulation and sulfate radical oxidation based on $\mathrm{Fe}^{2+}$ activation for leachate secondary effluent was studied, and it proved to be an efficient and promising method.

Coagulation performance is significantly better when the novel magnetic coagulant MFPFS was prepared by introducing $\mathrm{Fe}_{3} \mathrm{O}_{4}$ nanoparticles into PFS as applied in treating leachate secondary effluent when PFS is used alone. $\mathrm{Fe}_{3} \mathrm{O}_{4}$ nanoparticles can improve floc density and settling performance, thereby enhancing pollutant removal from the wastewater. The optimum mass ratio of $\mathrm{Fe}_{3} \mathrm{O}_{4} /$ PFS for preparing MFPFS is 1:3. Without adjusting $\mathrm{pH}$, at a dosage of $1.2 \mathrm{~g} / \mathrm{L}$ the removal rates of COD and color reach up to $60 \%$ and $80 \%$, respectively.

The oxidation efficiencies were affected by the factors of $\mathrm{Na}_{2} \mathrm{~S}_{2} \mathrm{O}_{8}$ dosage, $\mathrm{Fe}^{2+} / \mathrm{S}_{2} \mathrm{O}_{8}{ }^{2-}$ molar ratio, wastewater $\mathrm{pH}$, and temperature. With a $2.0 \mathrm{~g} / \mathrm{L} \mathrm{Na}_{2} \mathrm{~S}_{2} \mathrm{O}_{8}$ dosage, $0.3 \mathrm{Fe}^{2+} / \mathrm{S}_{2} \mathrm{O}_{8}^{2-}$ molar ratio, $\mathrm{pH} 3$, and $60^{\circ} \mathrm{C}$ temperature as the optimum working conditions for the treatment of effluent from MFPFS coagulation, sulfate radical oxidation due to $\mathrm{Fe}^{2+}$ activation could efficiently remove the residual contaminants, and the COD and color removals can reach up to $73 \%$ and $95 \%$, respectively.

Apart from good efficiencies of COD and color obtained, the combined process can also efficiently remove other parameters like $\mathrm{BOD}$, total nitrogen, and ammonia nitrogen. After being treated by the combined process, no violations of Chinese effluent standards for landfill leachate were found in respect to each individual parameter. The encouraging results demonstrated that the combined process could remove most target compounds and provide a viable alternative to the treatment of leachate secondary effluent.

\section{Acknowledgements}

This work was supported by the National Natural Sciences Foundation of China (No. 51468016), the Natural Sciences Foundation of Jiangxi (No. 20142BAB203027), and the Technology Development Research Project of Jiangxi (No. 20151BBG70020).

\section{References}

1. GOTVAJN A.Z., TISLER T., ZAGORC-KONCAN J. Comparison of different treatment strategies for industrial landfill leachate. J. Hazard. Mater., 162 (2-3), 1446, 2009.

2. MAHMUD K., HOSSAIN M.D., SHAMS S. Different treatment strategies for highly polluted landfill leachate in developing countries. Waste Manage., 32 (11), 2096, 2012.

3. FERNANDES A., PACHECO M.J., CIRÍACO L., LOPES A. Review on the electrochemical processes for the treatment of sanitary landfill leachates: Present and future. Appl. Catal., B, 176-177, 183, 2015.

4. HE P.J., ZHENG Z., ZHANG H., SHAO L.M., TANG Q.Y. PAEs and BPA removal in landfill leachate with Fenton process and its relationship with leachate DOM composition. Sci. Total Environ., 407 (17), 4928, 2009.

5. NTAMPOU X., ZOUBOULIS A.I., SAMARAS P. Appropriate combination of physico-chemical methods (coagulation/flocculation and ozonation) for the efficient treatment of landfill leachates. Chemosphere, 62 (5), 722, 2006.

6. GANDHIMATHI R., DURAI N.J., NIDHEESH P.V., RAMESH S.T., KANMANI S. Use of combined coagulationadsorption process as pretreatment of landfill leachate. Iran. J. environ. Healt., 10 (1), 1, 2013.

7. LI W., HUA T., ZHOU Q., ZHANG S., LI F. Treatment of stabilized landfill leachate by the combined process of coagulation/flocculation and powder activated carbon adsorption. Desalination, 264 (1-2), 56, 2010.

8. SONI A., TIWARI A., BAJPAI A.K. Removal of malachite green from aqueous solution using nano-iron oxide-loaded 
alginate microspheres: batch and column studies. Res. Chem. Intermediat., 40 (3), 913, 2014.

9. ZHANG M., XIAO F., XU X.Z., WANG D.S. Novel ferromagnetic nanoparticle composited PACls and their coagulation characteristics. Water Res., 46 (1), 127, 2012.

10. JIANG C., WANG R., MA W. The effect of magnetic nanoparticles on Microcystis aeruginosa removal by a composite coagulant. Colloids Surf., A, 369 (1-3), 260, 2010.

11. HONG M.K., PARK B.J., CHOI H.J. Preparation and physical characterization of polyacrylamide coated magnetite particles. Physica Status Solidi a-Applications and Materials Science, 204 (12), 4182, 2007.

12. LIU X., HU Q., FANG Z., ZHANG X., ZHANG B. Magnetic Chitosan Nanocomposites: A Useful Recyclable Tool for Heavy Metal Ion Removal. Langmuir, 25 (1), 3, 2009.

13. TURRO E., GIANNIS A., COSSU R., GIDARAKOS E., MANTZAVINOS D., KATSAOUNIS A. Electrochemical oxidation of stabilized landfill leachate on DSA electrodes. J. Hazard. Mater., 190 (1-3), 460, 2011.

14. FERNANDES A., SPRANGER P., FONSECA A.D., PACHECO M.J., CIRÍACO L., LOPES A. Effect of electrochemical treatments on the biodegradability of sanitary landfill leachates. Appl. Catal., B., 144, 514, 2014.

15. WANG P., ZENG G., PENG Y., LIU F., ZHANG, C., HUANG B., ZHONG Y., HE Y., LAI M. 2,4,6-Trichlorophenolpromoted catalytic wet oxidation of humic substances and stabilized landfill leachate. Chem. Eng. J., 247, 216, 2014.

16. XU X.Y., ZENG G.M., PENG Y.R., ZENG Z. Potassium persulfate promoted catalytic wet oxidation of fulvic acid as a model organic compound in landfill leachate with activated carbon. Chem. Eng. J., 200-202, 25, 2012.

17. CHYS M., OLOIBIRI V.A., AUDENAERT W.T.M., DEMEESTERE K., VAN HULLE S.W.H. Ozonation of biologically treated landfill leachate: efficiency and insights in organic conversions. Chem. Eng. J., 277, 104, 2015.

18. AMIRI A., SABOUR M.R. Multi-response optimization of Fenton process for applicability assessment in landfill leachate treatment. Waste Manag, 34 (12), 2528, 2014.

19. SILVA T.F., FERREIRA R., SOARES P.A., MANENTI D.R., FONSECAA., SARAIVA I., BOAVENTURA R.A., VILAR V.J. Insights into solar photo-Fenton reaction parameters in the oxidation of a sanitary landfill leachate at lab-scale. J. Environ. Manage., 164, 32, 2015.

20. ANFRUNS A., GABARRO J., GONZALEZ-OLMOS R., PUIG S., BALAGUER M.D., COLPRIM J. Coupling anammox and advanced oxidation-based technologies for mature landfill leachate treatment. J. Hazard. Mater., 258259, 27, 2013.

21. JI Y., FAN Y., LIU K., KONG D., LU J. Thermo activated persulfate oxidation of antibiotic sulfamethoxazole and structurally related compounds. Water Res., 87, 1, 2015.

22. FAN Y., JI Y., KONG D., LU J., ZHOU Q. Kinetic and mechanistic investigations of the degradation of sulfamethazine in heat-activated persulfate oxidation process. J. Hazard. Mater., 300, 39, 2015.

23. EPOLD I., DULOVA N. Oxidative degradation of levofloxacin in aqueous solution by $\mathrm{S}_{2} \mathrm{O}_{8}{ }^{2-} / \mathrm{Fe}^{2+}, \mathrm{S}_{2} \mathrm{O}_{8}{ }^{2-} / \mathrm{H}_{2} \mathrm{O}_{2}$ and $\mathrm{S}_{2} \mathrm{O}_{8}{ }^{2-} / \mathrm{OH}^{-}$processes: A comparative study. Journal of Environmental Chemical Engineering, 3 (2), 1207, 2015.

24. WANG C.W., LIANG C. Oxidative degradation of TMAH solution with UV persulfate activation. Chem. Eng. J., 254, 472, 2014.

25. SHARMA J., MISHRA I.M., DIONYSIOU D.D., KUMAR V. Oxidative removal of Bisphenol A by UV-C/ peroxymonosulfate (PMS): Kinetics, influence of coexisting chemicals and degradation pathway. Chem. Eng. J., 276, 193, 2015.

26. KUSHIDA M., KOIDE T., OSADA I., IMAIZUMI Y., KAWASAKI K., SUGAWARA T. Fabrication of $\mathrm{Fe}_{3} \mathrm{O}_{4} / \mathrm{SiO}_{2}$ core-shell nanoparticle monolayer as catalyst for carbon nanotube growth using Langmuir-Blodgett technique. Thin Solid Films, 537, 252, 2013

27. LIU X., LI X.-M., YANG Q., YUE X., SHEN T.-T., ZHENG W., LUO K., SUN Y.-H., ZENG G.-M. Landfill leachate pretreatment by coagulation-flocculation process using iron-based coagulants: Optimization by response surface methodology. Chem. Eng. J., 200-202, 39, 2012.

28. LI S.X., WEI D., MAK N.K., CAI Z., XU X.R., LI H.B., JIANG Y. Degradation of diphenylamine by persulfate: Performance optimization, kinetics and mechanism. J. Hazard. Mater., 164 (1), 26, 2009. 